Article

\title{
Hydrogen Storage in Boron Nitride and Carbon Nanomaterials
}

\section{Takeo Oku}

Department of Materials Science, The University of Shiga Prefecture, Hassaka 2500, Hikone, Shiga 522-8533, Japan; E-Mail: oku@mat.usp.ac.jp; Tel.: +81-749-288-368; Fax: +81-749-288-590

Academic Editor: Enrico Sciubba

Received: 10 September 2014 / Accepted: 26 December 2014 / Published: 31 December 2014

\begin{abstract}
Boron nitride ( $\mathrm{BN})$ nanomaterials were synthesized from $\mathrm{LaB}_{6}$ and $\mathrm{Pd} /$ boron powder, and the hydrogen storage was investigated by differential thermogravimetric analysis, which showed possibility of hydrogen storage of $1-3 \mathrm{wt} \%$. The hydrogen gas storage in $\mathrm{BN}$ and carbon $(\mathrm{C})$ clusters was also investigated by molecular orbital calculations, which indicated possible hydrogen storage of 6.5 and $4.9 \mathrm{wt} \%$, respectively. Chemisorption calculation was also carried out for $\mathrm{B}_{24} \mathrm{~N}_{24}$ cluster with changing endohedral elements in BN cluster to compare the bonding energy at nitrogen and boron, which showed that $\mathrm{Li}$ is a suitable element for hydrogenation to the BN cluster. The BN cluster materials would store $\mathrm{H}_{2}$ molecule easier than carbon fullerene materials, and its stability for high temperature would be good. Molecular dynamics calculations showed that $\mathrm{a}_{2}$ molecule remains stable in a $\mathrm{C}_{60}$ cage at $298 \mathrm{~K}$ and $0.1 \mathrm{MPa}$, and that pressures over $5 \mathrm{MPa}$ are needed to store $\mathrm{H}_{2}$ molecules in the $\mathrm{C}_{60}$ cage.
\end{abstract}

Keywords: nanostructure; boron nitride; carbon; hydrogen gas storage; hydrogenation; molecular orbital calculation

\section{Introduction}

Hydrogen is a carrier with high energy density, and forms only water and heat. On the other hand, fossil fuels generate toxic fuels, such as $\mathrm{CO}_{x}, \mathrm{NO}_{x}$ and $\mathrm{SO}_{x}$. Therefore, clean hydrogen energy is expected as substitute of fossil fuel in the 21 st century, and gas storage ability more than $6.5 \mathrm{wt} \%$ is needed for car application according to the US Department of Energy. Although $\mathrm{LaNi}_{5} \mathrm{H}_{6}$ is already used as an $\mathrm{H}_{2}$ gas storage materials, the ability is only $1 \mathrm{wt} \%$ because of the large atomic number of La and $\mathrm{Ni}$ [1]. On the other hand, fullerene-like materials, which consist of light elements, such as boron, 
carbon and nitrogen, would store more $\mathrm{H}_{2}$ gas compared to the metal hydrides. Various works have been reported on hydrogen storage ability of carbon nanotubes, fullerenes and nanomaterials [1]. It was reported that multi-walled carbon nanotubes could absorb hydrogen from $1 \mathrm{wt} \%$ up to $4.6 \mathrm{wt} \%$. These results indicate carbon nanotubes might be a possible candidate of hydrogen storage materials although the evaluation of hydrogen storage measurements is necessary. Many studies on $\mathrm{H}_{2}$ gas storage in carbon $(\mathrm{C})$ nanomaterials have been reported [2-7]. Boron nitride $(\mathrm{BN})$ nanomaterials are also expected in prospective application because they provide good stability at high temperatures with high electronic insulation in air [8]. Hydrogen storage in BN nanomaterials has also been studied recently [9-16]. It is difficult to absorb hydrogen by physisorption, both inside nanotubes and at the interstitial channels of nanotubes at room temperature, which is due to too weak bonding of physisorbed hydrogen to reach large storage at room temperature. Therefore, it is considered that chemisorption is a necessary requirement for hydrogen storage at room temperature. It was reported that chemisorption ratio observed at room temperature increases with increasing alkali/carbon rate. Therefore, if the energy of chemisorption can be lowered, hydrogen storage ability of carbon and BN nanotubes would be improved.

The purpose of the present study is twofold. The first is to prepare BN nanotubes, nanocapsules and nanocages, and to investigate hydrogen gas storage by thermogravimetry/differential thermogravimetric analysis (TG/DTA) and first principle calculation. $\mathrm{LaB}_{6}$ and $\mathrm{Pd}$ were selected in order to take advantage of their catalytic effect to produce the BN nanomaterials. La has shown excellent catalytic properties for producing a large number of single-walled carbon nanotubes and enlarging their diameter, and $\mathrm{Pd}$ is also expected to act as a hydrogen storage material. Although gas storage of hydrogen and argon in carbon nanotubes has been reported, carbon nanotubes are oxidized at $600{ }^{\circ} \mathrm{C}$ in air. On the other hand, BN starts to be oxidized into boron oxide and nitrogen $\sim 900{ }^{\circ} \mathrm{C}$ in air, which indicates excellent heat resistance compared to carbon materials for gas storage. The differences between $\mathrm{BN}$ and $\mathrm{C}$ nanomaterials are summarized as shown in Table 1. To understand the formation of BN nanostructures, high-resolution electron microscopy (HREM) were carried out, which are very powerful methods for atomic structure analysis [17,18]. For the BN nanomaterials, hydrogen gas storage measurements were carried out using TG/DTA.

Table 1. Differences between boron nitride $(\mathrm{BN})$ and $\mathrm{C}$ nanomaterials.

\begin{tabular}{ccc}
\hline Properties & BN & C \\
\hline Structure & $4-, 6-, 8$-membered rings & $5-, 6-, 7$-membered rings \\
Oxidation resistance & $\sim 900^{\circ} \mathrm{C}$ & $\sim 600{ }^{\circ} \mathrm{C}$ \\
Electronic property & Insulator & Metal-semiconductor \\
Energy gap (eV) & $\sim 6$ & $0-1.7$ \\
Band structure & Direct transition & Indirect transition \\
\hline
\end{tabular}

The second purpose of the present work is to investigate $\mathrm{H}_{2}$ gas storage ability of $\mathrm{BN}$ and $\mathrm{C}$ fullerene-like materials by theoretical calculation. Although huge amount of calculation is required to calculate nanotubes, it is considered that $\mathrm{H}_{2}$ molecules enter from the cap of nanotubes. Energy of chemisorption and stable hydrogen position inside the clusters were investigated as cap structures of nanotubes. Influence of endohedral element on $\mathrm{H}_{2}$ gas storage ability of $\mathrm{BN}$ fullerene-like materials 
was also investigated by theoretical calculations. Energy of chemisorption was investigated for cage clusters as a cap structure of nanotubes, and $\mathrm{B}_{24} \mathrm{~N}_{24}$ clusters, reported by mass spectrometry [8,19], were selected for the storage material. Li, $\mathrm{K}$ and $\mathrm{Na}$ elements were also selected for the doping atoms because these elements are of high electropositive character. The present study will give us a guideline for hydrogenation of $\mathrm{BN}$ nanomaterials as hydrogen storage materials.

\section{Experimental Procedures and Calculation Methods}

Mixture powder compacts made of boron particles (99\%, $40 \mathrm{~mm}$, Nilaco Corp., Tokyo, Japan), $\mathrm{LaB}_{6}$ particles $(99 \%, 1 \mathrm{~mm}$, Wako Pure Chemical Industries Ltd., Osaka, Japan) and Pd particles (99.5\%, $0.1 \mathrm{~mm}$, Nilaco Corp., Tokyo, Japan), with the size of $3 \mathrm{~mm}$ in height and $30 \mathrm{~mm}$ in diameter were produced by pressing powder at $10 \mathrm{MPa}$. The atomic ratios of metal (M) to boron (B) were in the range of 1:1-1:10. The green compacts were set on a copper mold in an electric-arc furnace, which was evacuated down to $2.0 \times 10^{-3} \mathrm{~Pa}$. After introducing a mixed gas of Ar $0.025 \mathrm{MPa}$ and $\mathrm{N}_{2} 0.025$ $\mathrm{MPa}$, arc-melting was applied to the samples at an accelerating voltage of $200 \mathrm{~V}$ and an arc current of 125 A for $2 \mathrm{~s}$. Arc-melting was performed with a vacuum arc-melting furnace (NEV-AD03, Nissin Giken, Saitama, Japan), and the white/gray BN nanomaterial powders were collected from surface of the bulk. Samples for HREM observation were prepared by dispersing the materials on holy carbon grids. HREM observation was performed with a $300 \mathrm{kV}$ electron microscope (JEM-3000F, JEOL, Tokyo, Japan). To confirm the formation of $\mathrm{BN}$ fullerene materials, energy dispersive $\mathrm{x}$-ray spectroscopy analysis was performed using the EDAX system with a probe size of $\sim 10 \mathrm{~nm}$. In order to measure hydrogen gas storage in $\mathrm{BN}$ nanomaterials, $\mathrm{BN}$ nanomaterials were extracted from the obtained powder by a supersonic dispersing method based on the Stokes equation using ethanol. The Stokes equation is expressed as follows:

$$
v=d^{2}(\sigma-\rho) \mathrm{g} / 18 \eta(h=v t ; v: \text { sedimentation rate })
$$

where $\eta$ is the viscosity of liquid; $\sigma$ is the density of particles; $\rho$ is the density of liquid; $g$ is the gravitational acceleration; $d$ is the diameter of particles; $t$ is the subsidence time; and $h$ is the height of liquid. Since there is a big difference in the size and density of the produced BN nanocapsules/nanotubes and other powders, it is believed that this method would be effective for separation of $\mathrm{BN}$ nanomaterials [20]. After separation of $\mathrm{BN}$ nanomaterials, hydrogen storage was measured by TG/DTA at temperatures in the range of $20-300{ }^{\circ} \mathrm{C}$ in $\mathrm{H}_{2}$ atmosphere [21].

To search the optimized structure of $\mathrm{B}_{99} \mathrm{~N}_{99}$ and $\mathrm{B}_{36} \mathrm{~N}_{36}$ with $\mathrm{H}_{2}$ molecules, semi-empirical molecular orbital calculations (parameterized model revision 3, PM3) were performed. The energies of $\mathrm{B}_{36} \mathrm{~N}_{36}$ with $\mathrm{H}_{2}$ molecules were calculated by first principle single point energy calculation using Gaussian. In the calculation, 3-21G was used as ground function with Hartree-Fock level. $\mathrm{B}_{24} \mathrm{~N}_{24}$, $\mathrm{B}_{36} \mathrm{~N}_{36}, \mathrm{~B}_{60} \mathrm{~N}_{60}$ and $\mathrm{C}_{60}$ were selected for cluster calculations. To investigate the optimized structures, semi-empirical molecular orbital calculations (parameterized model revision 5, PM5) were performed by using MOPAC. Eigenvector following (EF) method was used for geometry optimization, and charge is 0 . The default self-consistent method was restricted Hartree-Fock (HF). Multi-electron configuration interaction (MECI) was used in order to prevent repulsion between electrons becoming 
excessive. Chemisorption calculations of hydrogen atoms were performed for $\mathrm{B}_{24} \mathrm{~N}_{24}, \mathrm{~B}_{36} \mathrm{~N}_{36}$ and $\mathrm{C}_{60}$ by PM5 calculations [22,23].

$\mathrm{M} @ \mathrm{~B}_{24} \mathrm{~N}_{24}\left(\mathrm{M} @\right.$ : element encaged in $\left.\mathrm{B}_{24} \mathrm{~N}_{24}\right)$ was selected for cluster calculations. To investigate the optimized structures and the chemisorption calculations of hydrogen atoms, molecular orbital calculations were performed by using PM5 in MOPAC. The EF method was used for geometry optimization. The default self-consistent method was restricted as HF, and the MECI was used. In the calculation, chemisorption of hydrogen was performed on boron and nitrogen positions outside the cage [24]. Energy levels and densities of states (DOS) for $\mathrm{B}_{24} \mathrm{~N}_{24}$ and $\mathrm{Li} @ \mathrm{~B}_{24} \mathrm{~N}_{24}$ were also calculated by the first principles calculation with discrete variational (DV)-X $\alpha$ method.

Molecular dynamics calculations were carried out to confirm the stability of $\mathrm{H}_{2}$ molecules into $\mathrm{C}_{60}$ at $298 \mathrm{~K}$ and 0.1 MPa [25]. Number, temperature, and pressure (NTP) ensembles were used in the calculation as follows: number of atoms $(N)$, temperature $(T)$ and pressure $(P)$ are constant. Conditions of $\mathrm{H}_{2}$ gas storage were also calculated. Number, temperature, and enthalpy (NPH) ensembles were used in the calculation as follows: number of atoms $(N)$, pressure $(P)$ and enthalpy $(H)$ are constant. These molecular dynamics were calculated by organic potential.

\section{Results and Discussion}

\subsection{Synthesis of Boron Nitride Nanomaterials}

For some metals, formation enthalpies with boron $\left(\mathrm{H}^{\text {for }} \mathrm{B}\right)$ and nitrogen $\left(\mathrm{H}^{\text {for }} \mathrm{N}\right)$ are indicated in Figure 1a,b, respectively. The data were from theoretical calculations [8]. Difference of formation enthalpy $\left(\mathrm{H}^{\text {for }} \mathrm{N}-\mathrm{H}^{\text {for }} \mathrm{B}\right)$ is also shown in Figure 1c. The difference of formation enthalpy $\left(\mathrm{H}^{\text {for }} \mathrm{N}-\mathrm{H}^{\text {for }} \mathrm{B}\right)$ is very important for the formation of $\mathrm{BN}$ fullerene nanomaterials, because reactivity with nitrogen and boron is decided by this enthalpy. Basically, BN nanotubes are formed when rare earth metals are used as catalytic metals, such as $\mathrm{Y}, \mathrm{Zr}, \mathrm{Nb}, \mathrm{Hf}, \mathrm{Ta}, \mathrm{W}$ and La. These elements have minus enthalpy, as shown in Figure 1c. It means that catalytic elements for synthesis of BN nanotubes should be selected from those with minus formation enthalpy $\left(\mathrm{H}^{\text {for }} \mathrm{N}-\mathrm{H}^{\text {for }} \mathrm{B}\right)$. From the present guideline, Sc element could be a good catalytic element to form BN nanotubes. The detailed formation mechanism of the nanostructures with different metals should be investigated further.

A HREM image of a $\mathrm{BN}$ nanotube produced using $\mathrm{LaB}_{6}$ powder is shown in Figure 2a. In Figure $2 \mathrm{a}$, the diameter of the five-layered $\mathrm{BN}$ nanotube is changing from bottom to top, and amorphous patches are observed mostly at the top. Low magnification images of BN nanostructures were reported [17,20]. A HREM image of $\mathrm{BN}$ nanocage produced from $\mathrm{LaB}_{6} / \mathrm{B}$ powder is shown in Figure 2b, which indicates square-like shape, and four-membered rings of BN exist at the corner of the cage. The BN nanocage has a network-like structure, whose atomic arrangement is basically consistent with the $\mathrm{B}_{36} \mathrm{~N}_{36}$ cluster structure [8]. BN nanocapsules with $\mathrm{Pd}$ nanoparticles were also produced as shown in Figure 2c, and Pd nanoparticles were covered by a few BN layers. In order to confirm the formation of BN nanocapsules, EDX analysis was carried out, which showed the atomic ratio of $\mathrm{B}: \mathrm{N} \approx 1$. 
(a)

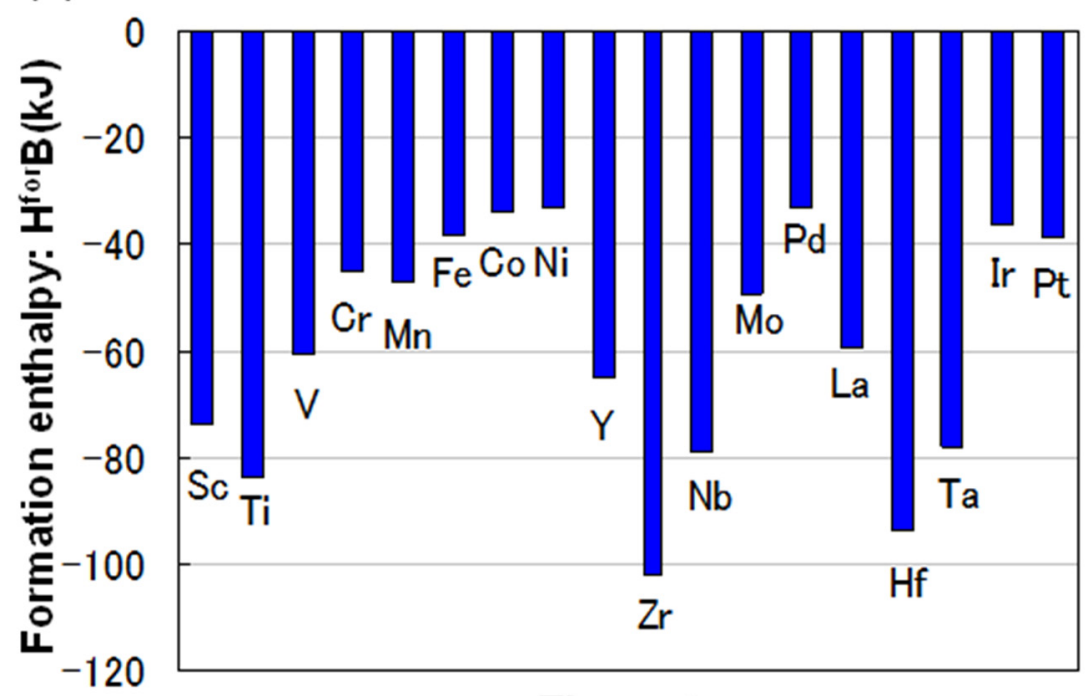

(b)

Elements

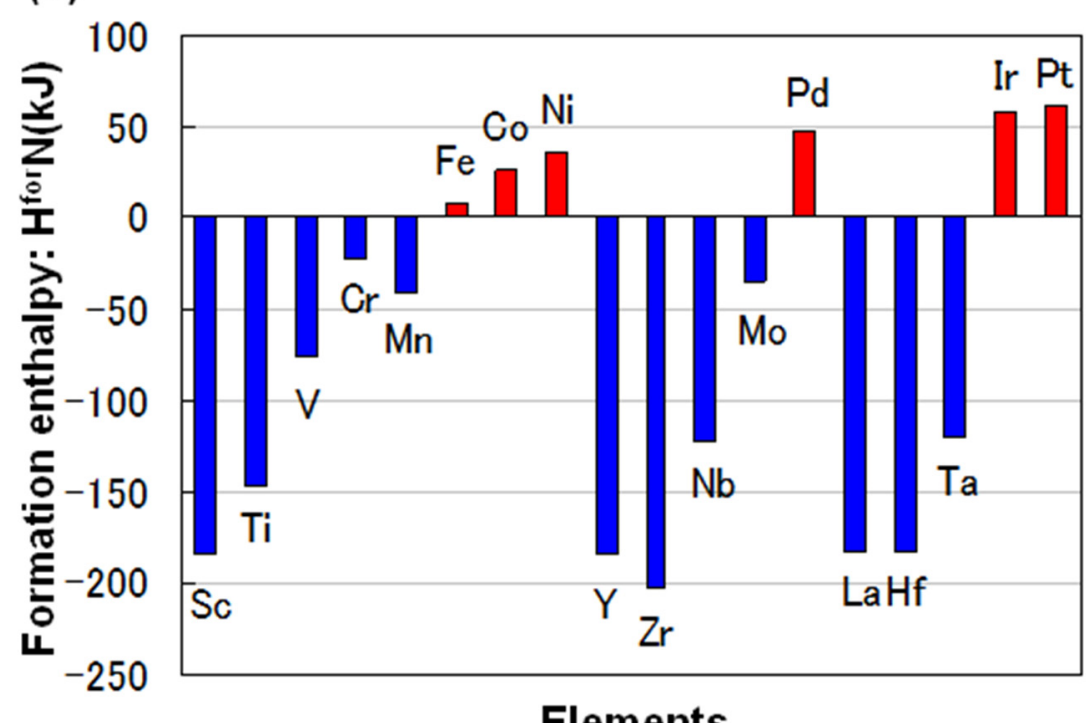

(c)

Elements

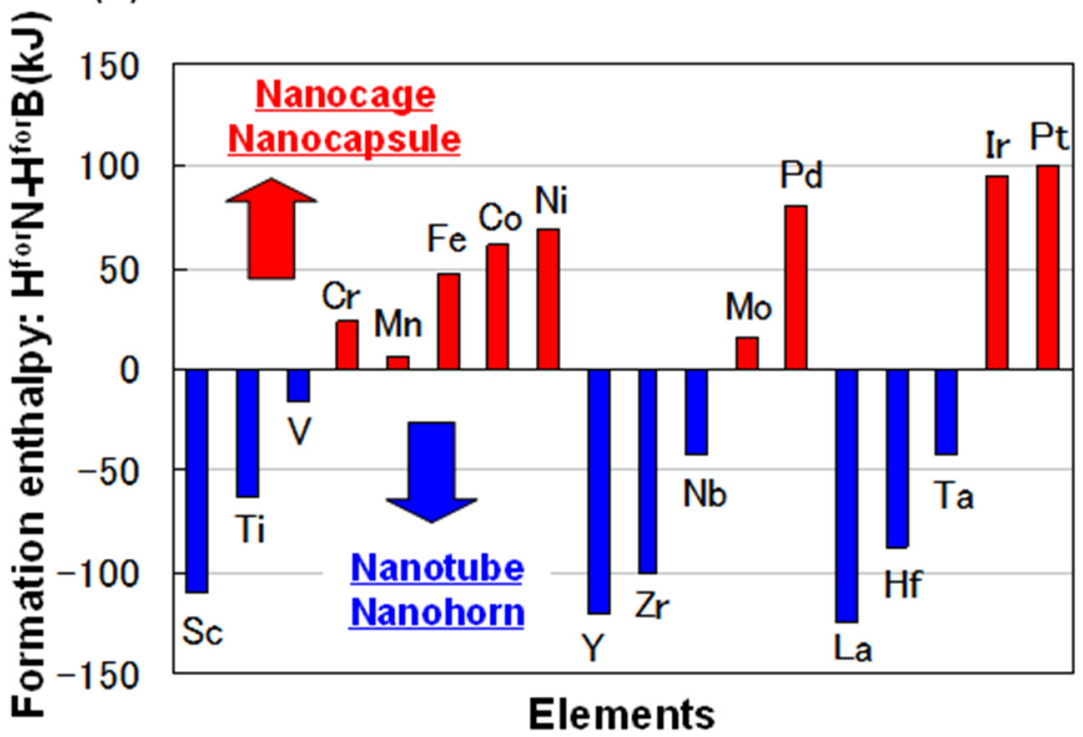

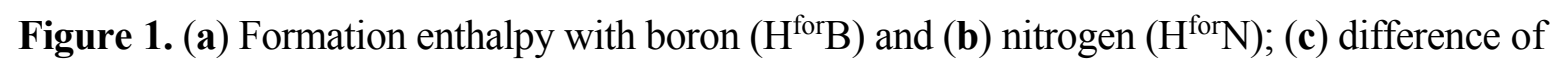
formation enthalpy $\left(\mathrm{H}^{\text {for }} \mathrm{N}-\mathrm{H}^{\text {for }} \mathrm{B}\right)$. 


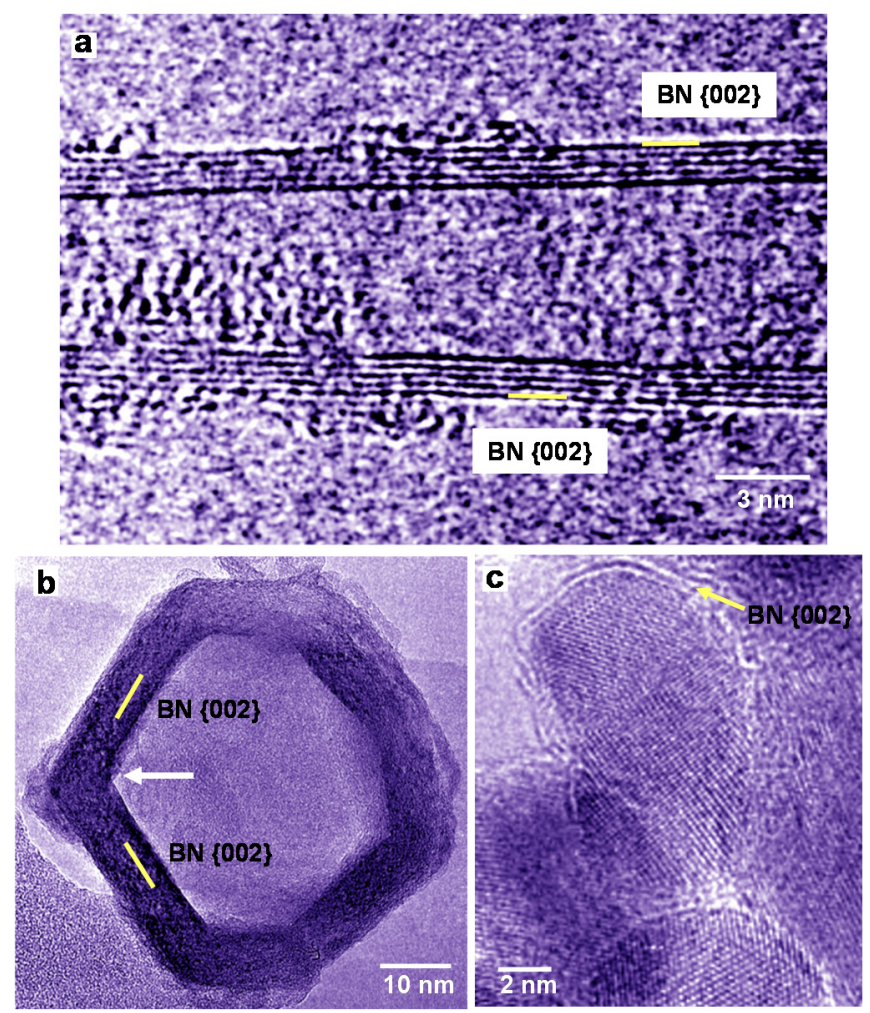

Figure 2. High-resolution electron microscopy (HREM) images of $\mathrm{BN}$ nanotube and $\mathrm{BN}$ nanocapsules produced using powder with ratios of: (a) $\mathrm{La}: \mathrm{B}=1: 6$; (b) $\mathrm{La}: \mathrm{B}=1: 4$; and (c) $\mathrm{Pd}: \mathrm{B}=1: 4$.

\subsection{Hydrogen Storage in Boron Nitride Nanomaterials Studied by Thermogravimetry/Differential} Thermogravimetric Analysis

DTA and TG curve of BN nanomaterials produced from $\mathrm{LaB}_{6}$ powder is shown in Figure 3. At a temperature around $70^{\circ} \mathrm{C}$, an increase of sample weight of $0.3 \mathrm{mg}$ is observed. Weight change for this sample was almost reversible, which indicates the reversibility of hydrogen adsorption. It also suggests that the hydrogen atoms would be physically absorbed. For the samples of $\mathrm{La}: \mathrm{B}=1: 6$ and $\mathrm{Pd}: \mathrm{B}=1: 4$, weight increases of $3.2 \%$ and $1.6 \%$ were observed, respectively, as listed in Table 2.

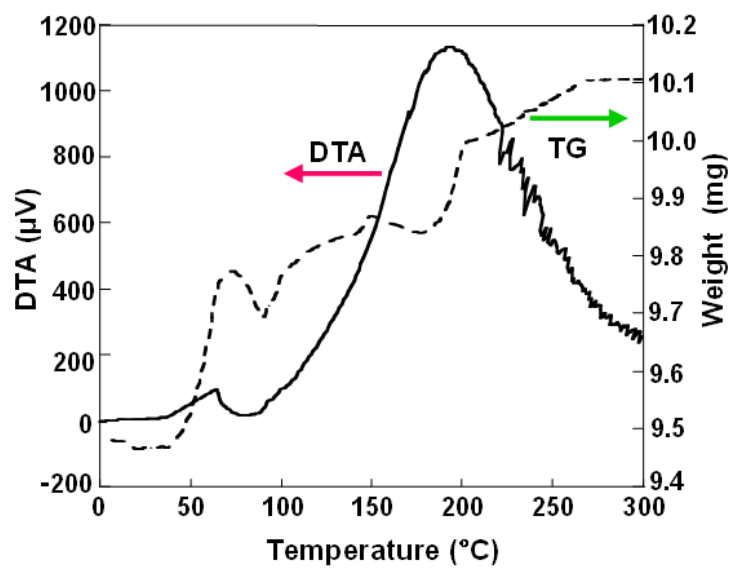

Figure 3. Differential thermogravimetric analysis (DTA) and thermogravimetry (TG) curve of BN nanocapsules and nanotubes produced using $\mathrm{LaB}_{6}$ powder. 
Table 2. Atomic ratio of starting materials, produced structures and hydrogen storage.

\begin{tabular}{ccc}
\hline M:B & Nanostructures & Weight change (wt\%) \\
\hline La:B $=1: 6$ & Nanotubes and nanocages & +3.2 \\
$\mathrm{La}: \mathrm{B}=1: 10$ & Nanotubes & +0.58 \\
$\mathrm{Pd}: \mathrm{B}=1: 4$ & Nanocapsules & +1.6 \\
\hline
\end{tabular}

$\mathrm{BN}$ nanostructures would have energy barriers for $\mathrm{H}_{2}$ molecules to pass through tetragonal and hexagonal rings. Figure 4 are structure models in which $\mathrm{H}_{2}$ molecule passes from hexagonal rings of $\mathrm{B}_{99} \mathrm{~N}_{99}$ and $\mathrm{B}_{36} \mathrm{~N}_{36}$. Single point energies were calculated with changing set point of $\mathrm{H}_{2}$ molecule from the center of the cage at intervals of $0.1 \mathrm{~nm}$. There is energy barrier that is given for $\mathrm{H}_{2}$ molecules to pass through the hexagonal rings. The energy barrier of $\mathrm{B}_{36} \mathrm{~N}_{36}$ hexagonal rings showed the smallest value of $14 \mathrm{eV}$ in the present calculation, which is smaller than that of $27 \mathrm{eV}$ at tetragonal rings. The $\mathrm{DE}$ of $\mathrm{C}_{60}$ hexagonal rings was also calculated to be $16 \mathrm{eV}$ for comparison. This value is higher than that of $\mathrm{B}_{36} \mathrm{~N}_{36}$ hexagonal rings, and the $\mathrm{H}_{2}$ molecule would pass from hexagonal rings of $\mathrm{B}_{36} \mathrm{~N}_{36}$ easier than from hexagonal rings of $\mathrm{C}_{60}$. It is known that $\mathrm{H}_{2}$ molecules are adsorbed on walls of single-walled carbon nanotubes over $7 \mathrm{MPa}$ as an experimental result. As a result of the comparison, $\mathrm{H}_{2}$ molecules enter into $\mathrm{B}_{36} \mathrm{~N}_{36}$ from hexagonal rings easier than tetragonal rings $\mathrm{B}_{36} \mathrm{~N}_{36}$ and hexagonal rings of $\mathrm{C}_{60}$.
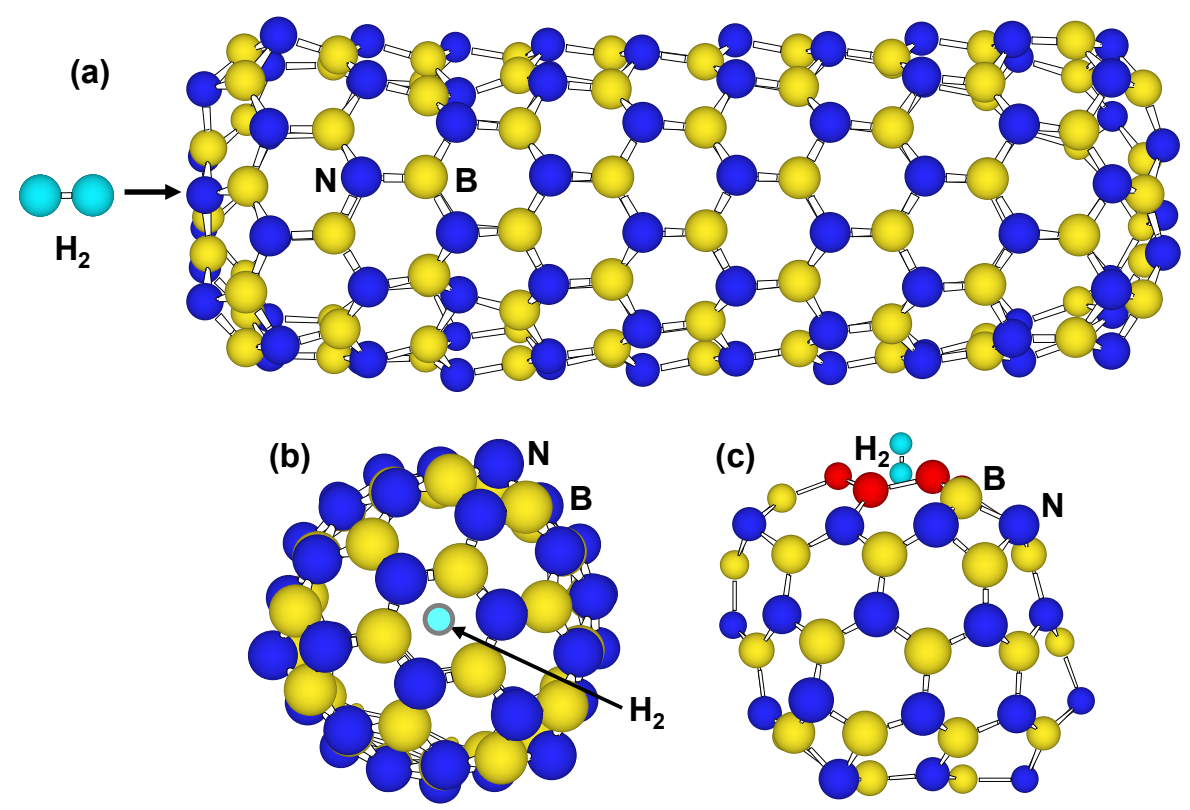

Figure 4. Structure models that $\mathrm{H}_{2}$ molecule passes through hexagonal $\mathrm{BN}$ rings of (a,b) tip of B $99 \mathrm{~N}_{99}$ nanotube and (c) $\mathrm{B}_{36} \mathrm{~N}_{36}$ cluster.

A formation mechanism of BN nanotubes and nanocapsules synthesized in the present work is described below. Metal and boron particles are melted by arc-melting, and during the solidification of the liquid into metal and/or boride nanoparticles, excess boron would react with nitrogen to form $\mathrm{BN}$ layers at the surface of the nanoparticles. Because of electrical insulation, BN fullerene materials are usually fabricated by arc-discharge method with specific conducting electrodes such as $\mathrm{HfB}_{2}$ and $\mathrm{ZrB}$. The present arc-melting method from mixed powder has two advantages for BN nanomaterial production. Since the powder becomes conducting by pressing, special electrodes are not needed. In 
addition, ordinary, commercial arc-melting furnaces can be used. These advantages indicate a simpler fabrication method compared to the ordinary arc-discharge methods.

Although gas storages of hydrogen and argon in carbon nanotubes have been reported, there are few reports for gas storage in $\mathrm{BN}$ fullerene materials and for calculations [21]. Weight increase of the sample in TG measurements was observed as shown in Figure 3. It might be due to the hydrogen gas storage in the BN nanomaterials. Since there would be metal and boron nanoparticles in the separated $\mathrm{BN}$ nanomaterials even after the separation, further qualification and evaluation of the samples are needed for hydrogen storage.

Carbon fullerenes and boron nitride fullerenes are sublimed at 600 and $1000{ }^{\circ} \mathrm{C}$, respectively. Boron nitride fullerenes would storage $\mathrm{H}_{2}$ molecules with smaller energy than carbon fullerenes, and would give good stability at high temperature. Boron nitride fullerene materials would be a better candidate for $\mathrm{H}_{2}$ storage materials.

\subsection{Molecular Orbital Calculations of Hydrogen Storage in Boron Nitride and C Clusters}

Figure 5 is a structural model of hydrogen atoms chemisorbed on boron and nitrogen for BN clusters and carbon clusters. Atoms bonded with hydrogen are moved outside from the clusters. Energies for hydrogen chemisorption on each position are summarized as Table 3. Hydrogen bonding with nitrogen is more stable than that with boron, and hydrogen bonding with carbon is more stable than $\mathrm{C}_{60}$. This result indicates the chemical modification of carbon fullerenes. When two hydrogen atoms were chemisorbed on carbon clusters, energies of carbon clusters increased.

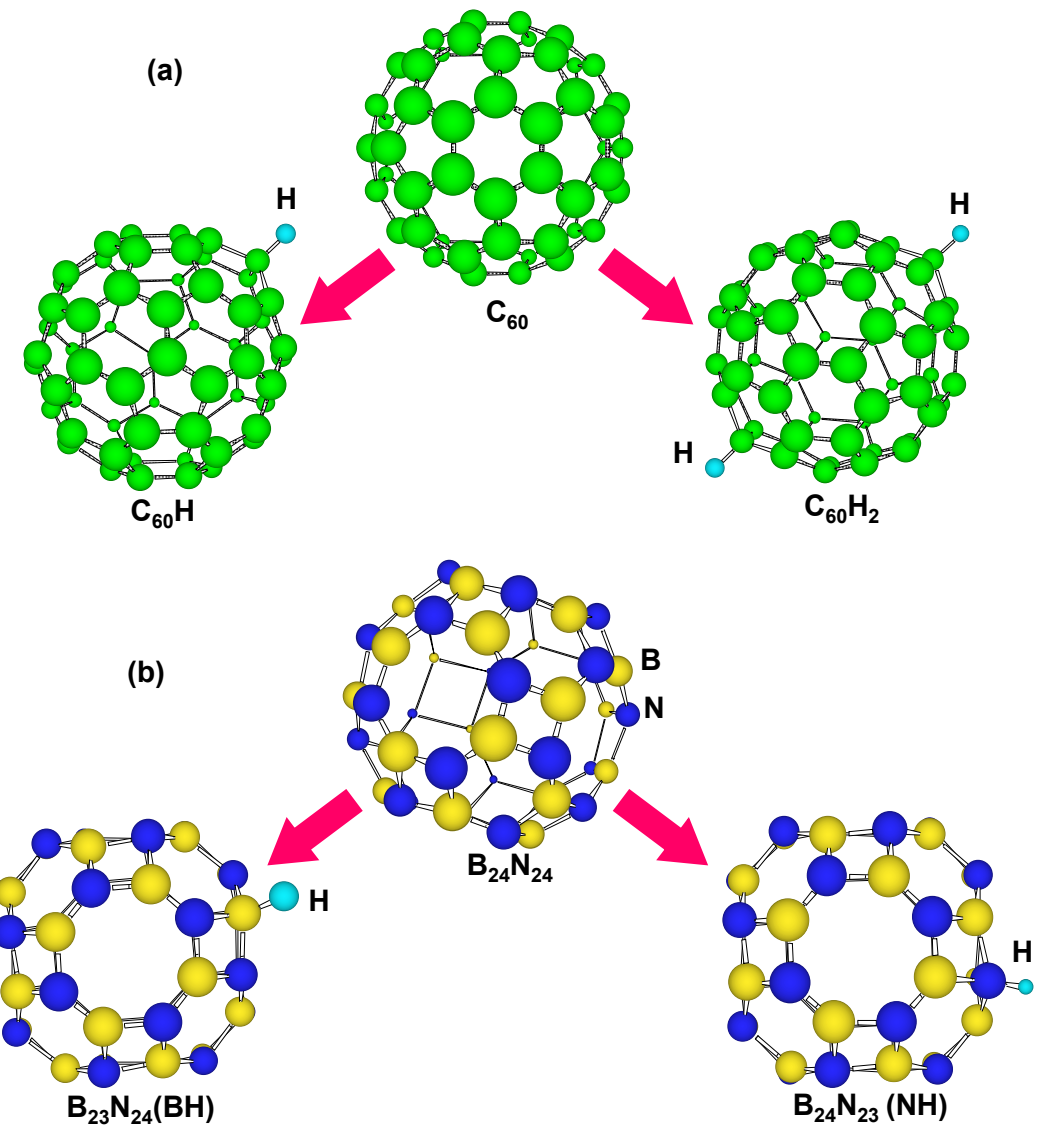

Figure 5. Structural models of $\mathrm{H}$ atoms chemisorbed on (a) $\mathrm{C}_{60}$ and (b) $\mathrm{B}_{24} \mathrm{~N}_{24}$. 
Table 3. Chemisorption energy of hydrogen $(\mathrm{H})$ atoms on $\mathrm{C}_{60}$ and $\mathrm{B}_{24} \mathrm{~N}_{24} . \Delta E=($ Heat of formation after hydrogen addition) - (Heat of formation before hydrogen addition).

\begin{tabular}{cccccc}
\hline \multirow{2}{*}{ Cluster } & \multirow{2}{*}{ Number of H atoms } & \multirow{2}{*}{ Additional position of $\mathbf{H}$} & \multicolumn{2}{c}{ Heat of formation $(\mathbf{e V})$} & \multirow{2}{*}{$\boldsymbol{*} \boldsymbol{E}(\mathbf{e V})$} \\
\cline { 4 - 5 } $\mathrm{C}_{60}$ & 1 & $\mathrm{C}$ & 35.21 & 35.03 & -0.18 \\
& 2 & $\mathrm{C}$ & 35.21 & 35.81 & 0.6 \\
\hline \multirow{2}{*}{$\mathrm{B}_{24} \mathrm{~N}_{24}$} & 1 & $\mathrm{~B}$ & -36.12 & -34.66 & 1.46 \\
& 1 & $\mathrm{~N}$ & -36.12 & -35.67 & 0.45 \\
\hline \multirow{2}{*}{$\mathrm{B}_{36} \mathrm{~N}_{36}$} & 1 & B of tetragonal ring & -69.33 & -67.83 & 1.50 \\
& 1 & N of tetragonal ring & -69.33 & -69.16 & 0.17 \\
& 1 & B of tetragonal ring & -69.33 & -67.51 & 1.83 \\
& 1 & N of tetragonal ring & -69.33 & -68.83 & 0.51 \\
\hline
\end{tabular}

In the calculation, chemisorption of hydrogen was performed on outside of cage, and on boron, nitrogen and carbon of tetragonal and hexagonal rings. The $\mathrm{B}_{36} \mathrm{~N}_{36}$ cluster has tetragonal and hexagonal BN rings, and there are four kinds of boron and nitrogen positions for the hydrogen chemisorption, as shown in Figure 6. For the stability calculations of $\mathrm{H}_{2}$ molecules in these clusters, $30 \mathrm{H}_{2}$ molecules were also introduced in $\mathrm{B}_{24} \mathrm{~N}_{24}, \mathrm{~B}_{36} \mathrm{~N}_{36}, \mathrm{~B}_{60} \mathrm{~N}_{60}$ and $\mathrm{C}_{60}$. Figure 5 is a structural model of hydrogen atoms chemisorbed on boron and nitrogen for $\mathrm{B}_{36} \mathrm{~N}_{36}$. Energies for hydrogen chemisorption on each position are summarized as Table 3. Hydrogen bonding with nitrogen is more stable than that with boron because nitrogen atoms are more electrophilic compared to boron atoms. In addition, hydrogen bonding on tetragonal ring is more stable than that of hexagonal ring. Chemisoption of hydrogen with $\mathrm{C}_{60}$ reduced the energy. When two hydrogen atoms were chemisorbed on carbon clusters, energies of carbon clusters increased.

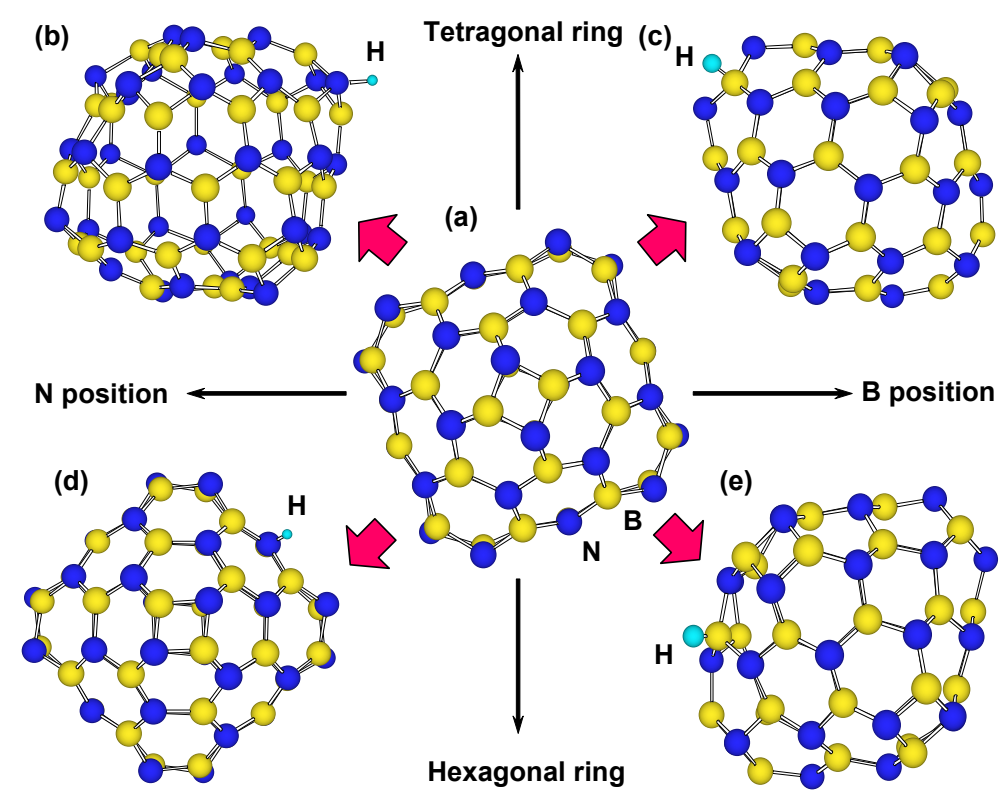

Figure 6. Structure models for hydrogen chemisorption on $\mathrm{B}_{36} \mathrm{~N}_{36}$ : (a) structural model of $\mathrm{B}_{36} \mathrm{~N}_{36}$; (b,c) structural models of hydrogen chemisorption on $\mathrm{N}$ and $\mathrm{B}$ positions of tetragonal BN ring, respectively; and (d,e) structural models of hydrogen chemisorbed on $\mathrm{N}$ and $\mathrm{B}$ positions of hexagonal $\mathrm{BN}$ ring, respectively. 
To investigate stability of $\mathrm{H}_{2}$ molecules in clusters, energies were calculated for $\mathrm{H}_{2}$ molecules introduced in the center of clusters. The structural models are shown in Figure 7. Energies of $\mathrm{C}_{60}$, $\mathrm{B}_{24} \mathrm{~N}_{24}, \mathrm{~B}_{36} \mathrm{~N}_{36}$ and $\mathrm{B}_{60} \mathrm{~N}_{60}$ were calculated to be $0.58,20.71,20.93$ and $20.82 \mathrm{eV} / \mathrm{mol}$ atom, respectively. This result indicates that $\mathrm{B}_{24} \mathrm{~N}_{24}, \mathrm{~B}_{36} \mathrm{~N}_{36}$ and $\mathrm{B}_{60} \mathrm{~N}_{60}$ with $\mathrm{H}_{2}$ molecules are more stable than $\mathrm{C}_{60}$ with $\mathrm{H}_{2}$ molecule, and that $\mathrm{B}_{36} \mathrm{~N}_{36}$ is the most stable in $\mathrm{BN}$ clusters.
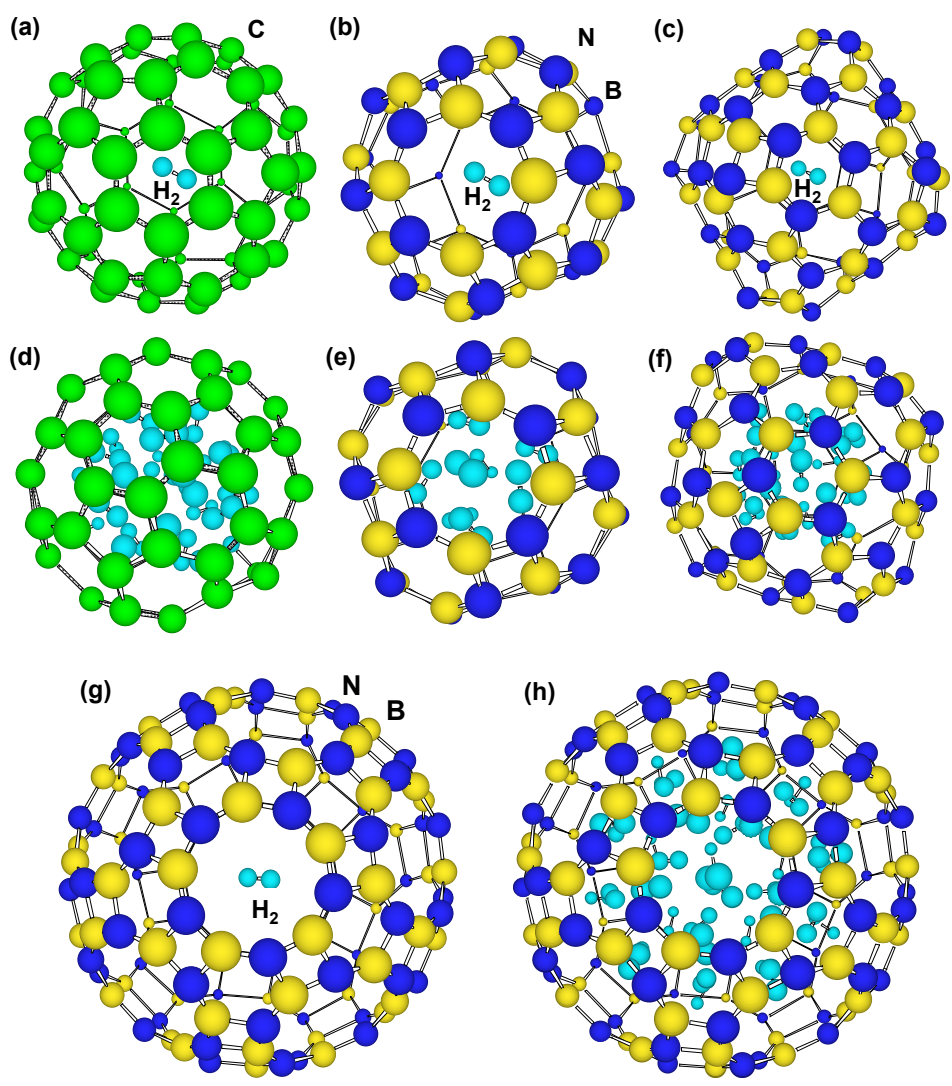

Figure 7. Optimized structural models of $\mathrm{H}_{2}$ molecules in the clusters. $\mathrm{A} \mathrm{H}_{2}$ molecule in the center of (a) $\mathrm{C}_{60}$; (b) $\mathrm{B}_{24} \mathrm{~N}_{24}$; (c) $\mathrm{B}_{36} \mathrm{~N}_{36}$; (d) $22 \mathrm{H}_{2}$ molecules inside $\mathrm{C}_{60}$ and 8 atoms chemisorbed; (e) $9 \mathrm{H}_{2}$ molecules in $\mathrm{B}_{24} \mathrm{~N}_{24}$; and (f) 20 molecules in $\mathrm{B}_{36} \mathrm{~N}_{36}$; (g) 1 and (h) $38 \mathrm{H}_{2}$ molecules in $\mathrm{B}_{60} \mathrm{~N}_{60}$.

Hydrogen storage $(\mathrm{wt} \%)$ of $\mathrm{B}_{60} \mathrm{~N}_{60}$ cluster was calculated, and structural models are shown in Figure 7. Other $\mathrm{C}_{60}, \mathrm{~B}_{24} \mathrm{~N}_{24}$ and $\mathrm{B}_{36} \mathrm{~N}_{36}$ were calculated, as summarized in Table 4. From Table 4, $\mathrm{C}$ and $\mathrm{BN}$ cluster showed possibility of hydrogen storage of $\sim 6.5$ and $\sim 4.9 \mathrm{wt} \%$, respectively.

Although hydrogen storage ( $\mathrm{wt}^{\%} \%$ ) of $\mathrm{C}_{60}$ is better than those of $\mathrm{BN}$ clusters, energy increase by hydrogen addition is higher for $\mathrm{C}_{60}(4.6-5.2 \mathrm{eV} / \mathrm{H}$ atom) compared to $\mathrm{BN}$ clusters $(1.0-3.1 \mathrm{eV} / \mathrm{H}$ atom), which would be due to $\mathrm{C}-\mathrm{H}$ interaction. This indicates that needed energy for hydrogen storage in $\mathrm{BN}$ clusters is lower compared to the $\mathrm{C}_{60}$. From Table 4, stability of $\mathrm{H}_{2}$ molecules in $\mathrm{B}_{24} \mathrm{~N}_{24}$ and $\mathrm{B}_{36} \mathrm{~N}_{36}$ seems to be higher than that of $\mathrm{C}_{60}$. Hydrogen atoms were calculated to be chemisorbed inside $\mathrm{C}_{60}$, as shown in Table 4. This indicates that inside of $\mathrm{C}_{60}$ also has good reactivity as well as outside of the cage. Chemisorption inside the $\mathrm{C}_{60}$ clusters may indicate that hydrogen capacity may gradually reduce under the adsorption-desorption cycles. On the other hand, BN clusters have no chemisorption inside the clusters, which indicates that the $\mathrm{BN}$ clusters would be a better candidate for stable adsorption-desorption 
cycles. $\mathrm{C}_{60}$ cluster shows the minimum energies in spite of the positive values. It is believed that p-electrons outside and inside of the cage would increase the energy. However, s-electrons in the 5- and 6-membered carbon rings would stabilize the cage structure. Hydrogen addition to the $\mathrm{C}_{60}$ decreased the energy, which agrees with the above description. The hydrogen storage of the present $\mathrm{BN}$ cluster was calculated to be $\sim 4.9 \mathrm{wt} \%$, and the measured values were $1-3 \mathrm{wt} \%$. This might be due to the remained catalytic metals in the sample, which reduces the storage ratio.

Table 4. Energy of clusters with hydrogen.

\begin{tabular}{cccccc}
\hline Cluster & Introduced $\mathbf{H}_{2}$ & $\begin{array}{c}\text { Heat of } \\
\text { formation }(\mathbf{e V})\end{array}$ & $\begin{array}{c}\text { H atoms } \\
\text { chemisorbed } \\
\text { inside cluster }\end{array}$ & $\begin{array}{c}\text { Hydrogen storage } \\
\mathbf{( w t \% )}\end{array}$ & $\begin{array}{c}\text { Heat of formation } \\
\text { per added H atom } \\
\text { (eV/H atom) }\end{array}$ \\
\hline \multirow{2}{*}{$\mathrm{C}_{60}$} & 0 & 35.21 & 0 & & \\
& 22 & 143.01 & 0 & $5.8-6.5$ & $4.9-5.2$ \\
\hline $\mathrm{B}_{24} \mathrm{~N}_{24}$ & 25 & 164.87 & 4 & & \\
\hline \multirow{2}{*}{$\mathrm{B}_{36} \mathrm{~N}_{36}$} & 0 & 169.63 & $8^{*}$ & 2.9 & 3.0 \\
\hline \multirow{2}{*}{$\mathrm{B}_{60} \mathrm{~N}_{60}$} & 0 & -36.12 & 0 & 4.3 & \multirow{2}{*}{3.1} \\
\hline
\end{tabular}

* A C-C bond was broken.

Although carbon nanotubes are oxidized at $\sim 600^{\circ} \mathrm{C}$, BN nanomaterials are almost stable $\sim 900{ }^{\circ} \mathrm{C}$ in air, which indicates $\mathrm{BN}$ fullerenes have higher thermal and chemical stability than those of carbon fullerenes. BN fullerenes with good thermal and chemical stability can store $\mathrm{H}_{2}$ molecules with less energy, and they have the same chemisorption energy and higher stability, compared to carbon clusters. BN fullerene materials would be better candidates for $\mathrm{H}_{2}$ storage materials.

\subsection{Effects of Endohedral Element in $B_{24} N_{24}$ Clusters on Hydrogenation}

Figure 8 is a structural model of hydrogen atoms chemisorbed on nitrogen position for $\mathrm{M} @ \mathrm{~B}_{24} \mathrm{~N}_{24}$. Energies for hydrogen chemisorption on boron and nitrogen positions are summarized as Table 5 . Heats of formation $(\mathrm{eV})$ of $\mathrm{M} @ \mathrm{~B}_{24} \mathrm{~N}_{24}$ by hydrogenation are indicated in Figure 9. In Table 5 and Figure 9, "None" means that metal catalyst was not encaged in $\mathrm{B}_{24} \mathrm{~N}_{24}$, and "BH" and "NH" means that hydrogen atom was chemisorbed on boron and nitrogen, respectively. Figure 9 shows that hydrogen bonding with nitrogen is more stable than that with boron because nitrogen atoms are more electrophilic compared to boron atoms. Figure 9 also indicates that energies of chemisorption on $\mathrm{M} @ \mathrm{~B}_{24} \mathrm{~N}_{24}$ are much lower than that of $\mathrm{B}_{24} \mathrm{~N}_{24}$. From this result, Li atom works as a good endohedral element for hydrogen chemisorption. Metal catalysts in the present work have been reported to generate hydrides such as $\mathrm{LiH}$ because of strong interaction between hydrogen and metal atoms. In the present work, it is clarified that $\mathrm{Li}$ doping and nitrogen positions are suitable for hydrogenation for the $\mathrm{B}_{24} \mathrm{~N}_{24}$ clusters. 

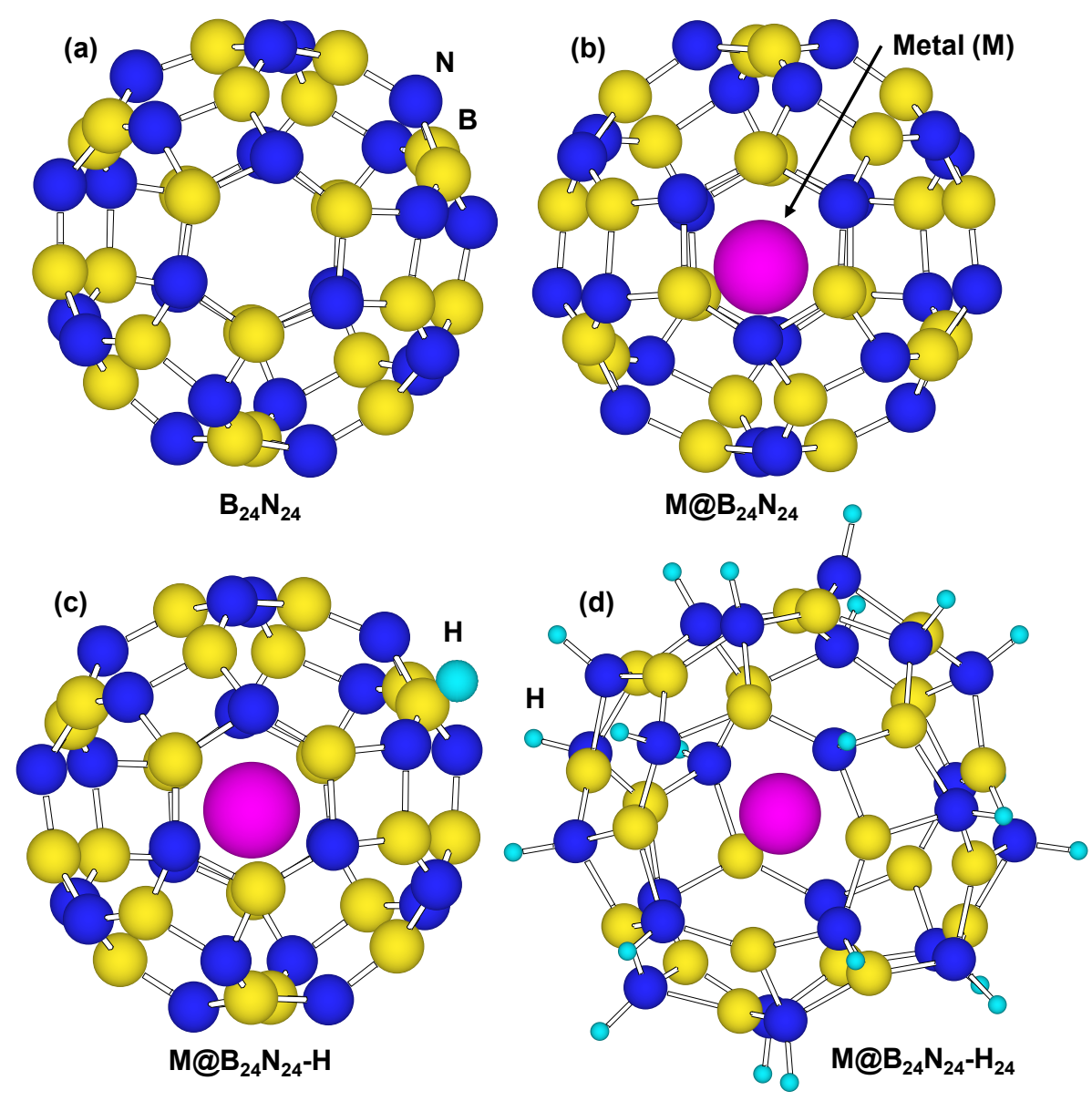

Figure 8. Structural models for (a) $\mathrm{B}_{24} \mathrm{~N}_{24}$; (b) endohedral $\mathrm{M} @ \mathrm{~B}_{24} \mathrm{~N}_{24}$; (c) hydrogenated $\mathrm{M} @ \mathrm{~B}_{24} \mathrm{~N}_{24}-\mathrm{H}$; and (d) $\mathrm{M} @ \mathrm{~B}_{24} \mathrm{~N}_{24}$ which chemisorbed 24 hydrogen atoms.

Table 5. Chemisorption energies of a hydrogen atom on $\mathrm{M} @ \mathrm{~B}_{24} \mathrm{~N}_{24}$.

\begin{tabular}{cccc}
\hline Cluster & Hydrogenation position & Heat of formation $(\mathbf{e V})$ & $\boldsymbol{\Delta} \boldsymbol{E} *(\mathbf{e V})$ \\
\hline & Un-hydrogenated & -36.12 & 0 \\
$\mathrm{~B}_{24} \mathrm{~N}_{24}$ & $\mathrm{~B}$ & -34.66 & 1.46 \\
& $\mathrm{~N}$ & -35.67 & 0.45 \\
\hline & Un-hydrogenated & -36.79 & 0 \\
$\mathrm{Li} @ \mathrm{~B}_{24} \mathrm{~N}_{24}$ & $\mathrm{~B}$ & -37.96 & -1.17 \\
& $\mathrm{~N}$ & -38.05 & -1.26 \\
\hline & Un-hydrogenated & -35.38 & 0 \\
$\mathrm{Na} @ \mathrm{~B}_{24} \mathrm{~N}_{24}$ & $\mathrm{~B}$ & -36.43 & -1.05 \\
& $\mathrm{~N}$ & -36.62 & -1.24 \\
\hline & Un-hydrogenated & -31.80 & 0 \\
$\mathrm{~K} @ \mathrm{~B}_{24} \mathrm{~N}_{24}$ & $\mathrm{~B}$ & -32.84 & -1.04 \\
& $\mathrm{~N}$ & -32.90 & -1.10 \\
\hline
\end{tabular}

$* \Delta E=$ (heat of formation after hydrogen addition) - (heat of formation before hydrogen addition). 


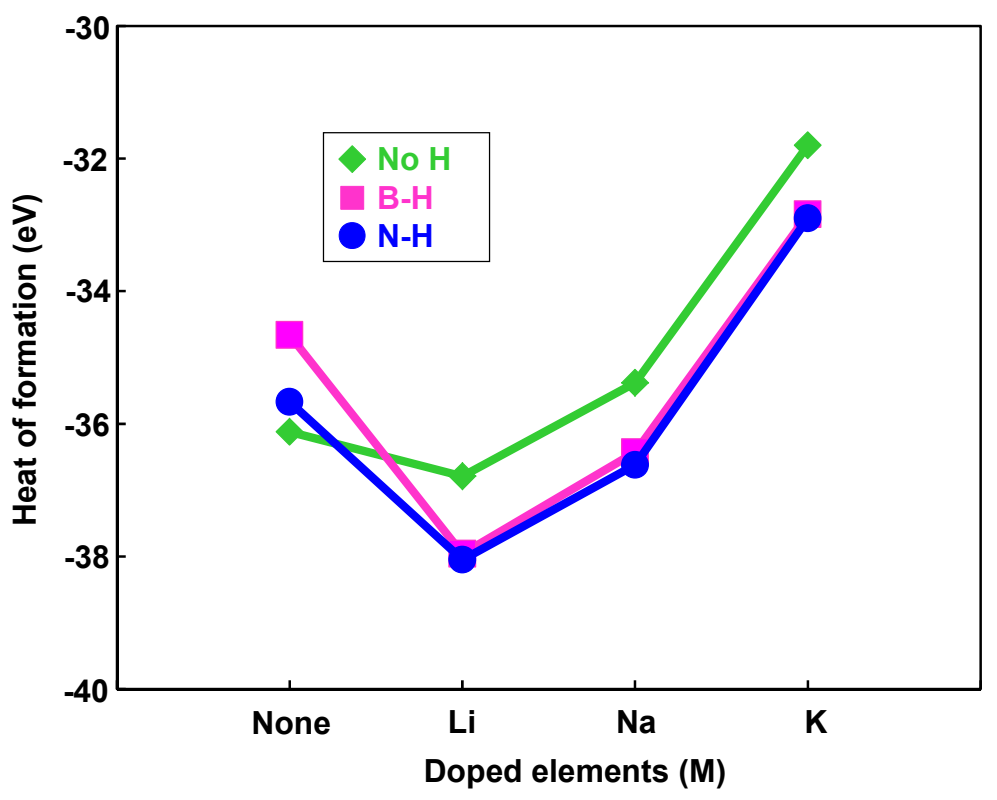

Figure 9. Heats of formation of hydrogenation for $\mathrm{M} @ \mathrm{~B}_{24} \mathrm{~N}_{24}$ clusters by endohedral elements.

Bond lengths of $\mathrm{B}-\mathrm{H}$ and $\mathrm{N}-\mathrm{H}$ for $\mathrm{M} @ \mathrm{~B}_{24} \mathrm{~N}_{24}$ are summarized in Table 6. B-H and N-H distance decreased by doping element in the BN cluster. Bond lengths of $\mathrm{N}-\mathrm{H}$ are shorter than that of $\mathrm{B}-\mathrm{H}$ for these $\mathrm{BN}$ clusters, and the bond length of $\mathrm{N}-\mathrm{H}$ for $\mathrm{Li} @ \mathrm{~B}_{24} \mathrm{~N}_{24}$ is the shortest. The endohedral atoms appear to decrease the repulsion energy between the electrons of the hydrogen atom and the p-electrons of $\mathrm{B}_{24} \mathrm{~N}_{24}$. Figure $8 \mathrm{~d}$ is a structural model of $\mathrm{M} @ \mathrm{~B}_{24} \mathrm{~N}_{24} \mathrm{H}_{24}$, which indicates hydrogenation on all nitrogen positions for $\mathrm{M} @ \mathrm{~B}_{24} \mathrm{~N}_{24}$, and the hydrogen storage capacity is summarized in Table 7. Li is also a good element for hydrogen storage capacity because Li is the lightest element of these. Energy levels and density of states for $\mathrm{B}_{24} \mathrm{~N}_{24}$ and $\mathrm{Li} @ \mathrm{~B}_{24} \mathrm{~N}_{24}$ are shown in Figure 10. Fermi levels in energy level diagrams and DOS diagrams correspond to $0 \mathrm{eV}$. $\mathrm{B}_{24} \mathrm{~N}_{24}$ and $\mathrm{Li} @ \mathrm{~B}_{24} \mathrm{~N}_{24}$ show energy gaps of 4.8873 and $0.0247 \mathrm{eV}$ between the highest occupied molecular orbital (HOMO) and the lowest unoccupied molecular orbital (LUMO), respectively. This means that electron of Li element transferred to the $\mathrm{B}_{24} \mathrm{~N}_{24}$ cage, and electronic state of $\mathrm{BN}$ cluster would change from semiconductor to metallic property by $\mathrm{Li}$ doping in $\mathrm{BN}$ clusters.

Table 6. Bond length of $\mathrm{B}-\mathrm{H}$ and $\mathrm{N}-\mathrm{H}$ on $\mathrm{M} @ \mathrm{~B}_{24} \mathrm{~N}_{24}$.

\begin{tabular}{ccc}
\hline Cluster & $\mathbf{B}-\mathbf{H}(\AA)$ & $\mathbf{N}-\mathbf{H}(\AA)$ \\
\hline $\mathrm{B}_{24} \mathrm{~N}_{24}$ & 1.229 & 1.010 \\
$\mathrm{Li} @ \mathrm{~B}_{24} \mathrm{~N}_{24}$ & 0.695 & 0.616 \\
$\mathrm{Na} @ \mathrm{~B}_{24} \mathrm{~N}_{24}$ & 1.203 & 1.005 \\
$\mathrm{~K} @ \mathrm{~B}_{24} \mathrm{~N}_{24}$ & 1.204 & 1.006 \\
\hline
\end{tabular}

Table 7. Hydrogen storage capacity of chemisorption on nitrogen position of $M @ B_{24} \mathrm{~N}_{24}$.

\begin{tabular}{cc}
\hline Cluster & Hydrogen storage (wt\%) \\
\hline $\mathrm{Li} @ \mathrm{~B}_{24} \mathrm{~N}_{24} \mathrm{H}_{24}$ & 3.86 \\
$\mathrm{Na} @ \mathrm{~B}_{24} \mathrm{~N}_{24} \mathrm{H}_{24}$ & 3.76 \\
$\mathrm{~K} @ \mathrm{~B}_{24} \mathrm{~N}_{24} \mathrm{H}_{24}$ & 3.67 \\
\hline
\end{tabular}


(a)

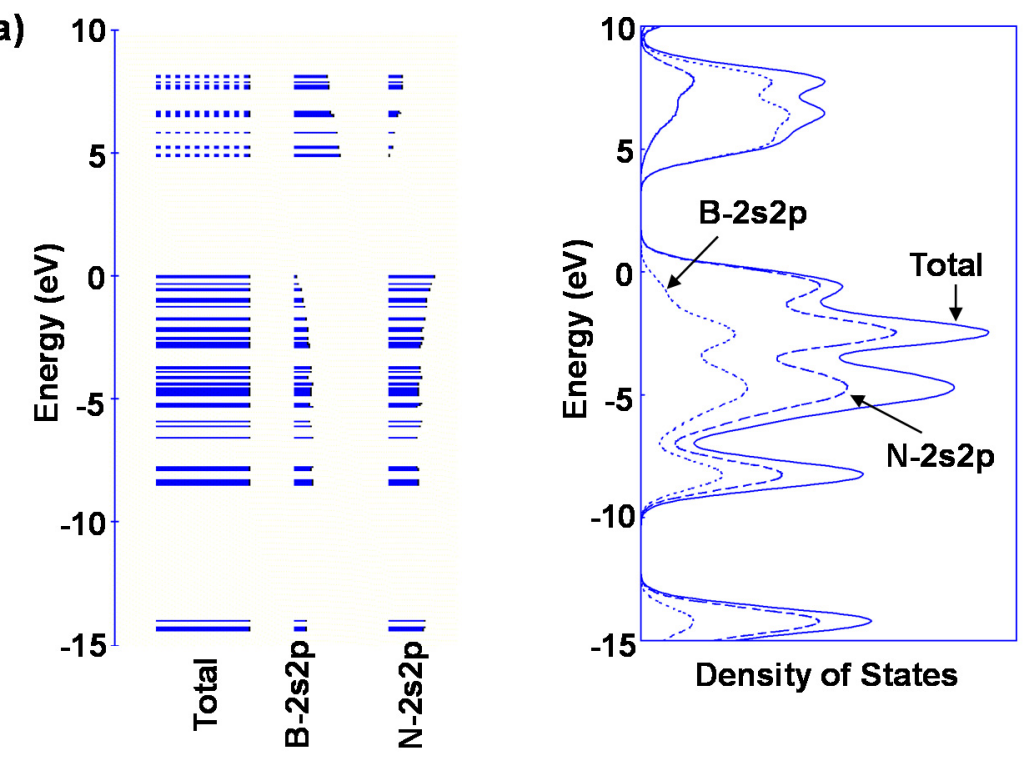

(b)

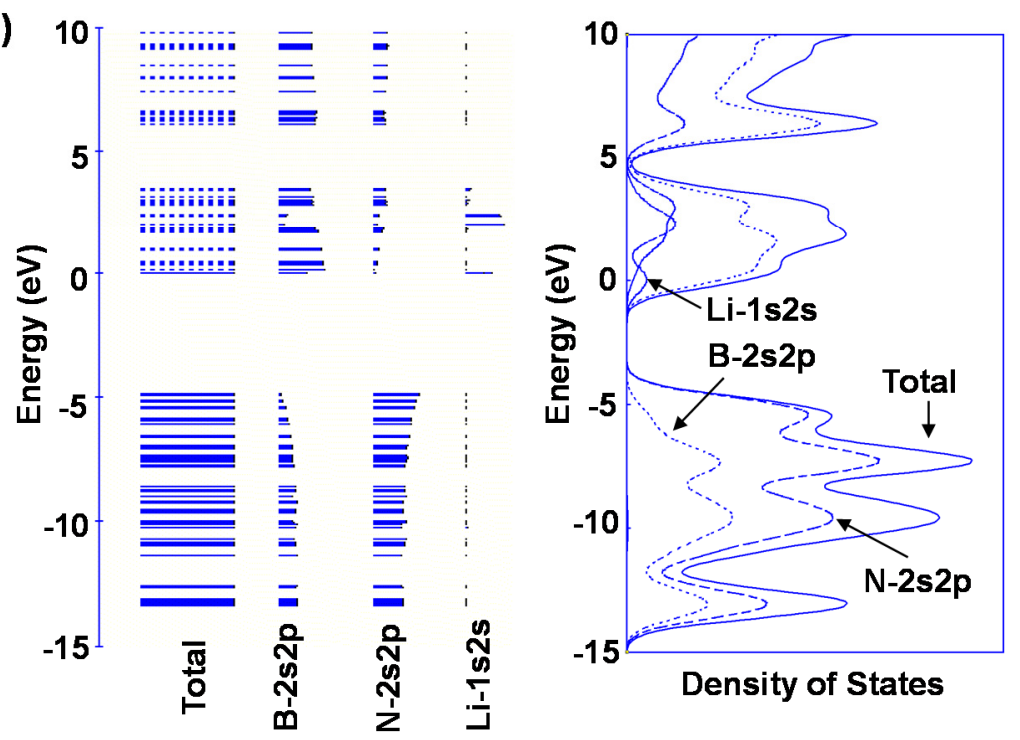

Figure 10. Energy levels diagrams and density of states of (a) $\mathrm{B}_{24} \mathrm{~N}_{24}$ and (b) $\mathrm{Li} @ \mathrm{~B}_{24} \mathrm{~N}_{24}$.

Although it was reported that BN nanotubes were produced by lithium vapor, synthesis of Li@BN has not been reported yet. BN fullerenes have high thermal and chemical stability, and M@BN fullerenes have lower energy of chemisorption compared to the present work. Since the BN clusters were reported to be doped with metal elements, $\mathrm{M} @ \mathrm{BN}$ clusters would be produced. BN fullerene materials with endohedral element such as Li would be better candidates for $\mathrm{H}_{2}$ storage materials.

\subsection{Molecular Dynamics Calculations of Hydrogen Storage in C60 Clusters}

$\mathrm{C}_{60}$ included a $\mathrm{H}_{2}$ molecule kept in stable state at $T=298 \mathrm{~K}$ and $P=0.1 \mathrm{MPa}$. This unit cell is shown in Figure 11. This model was calculated with $N=62$ atoms, $T=298 \mathrm{~K}$ and $P=0.1 \mathrm{MPa}$. Although the $\mathrm{H}_{2}$ molecule vibrated in the $\mathrm{C}_{60}$ cage, it was not discharged from the cage. Some $\mathrm{H}_{2}$ molecules were stored in the $\mathrm{C}_{60}$ cage when the pressure was $5 \mathrm{MPa}$. This unit cell is shown in Figure 12, which is composed of $32 \mathrm{C}_{60}(f c c)$ with $288 \mathrm{H}_{2}$ molecules $(f c c)$. This model was calculated with $N=2496$ atoms and $P=5 \mathrm{MPa}$. $\mathrm{H}_{2}$ molecules pass through the hexagonal rings of the $\mathrm{C}_{60}$ cage at $0.5 \mathrm{ps}$. 


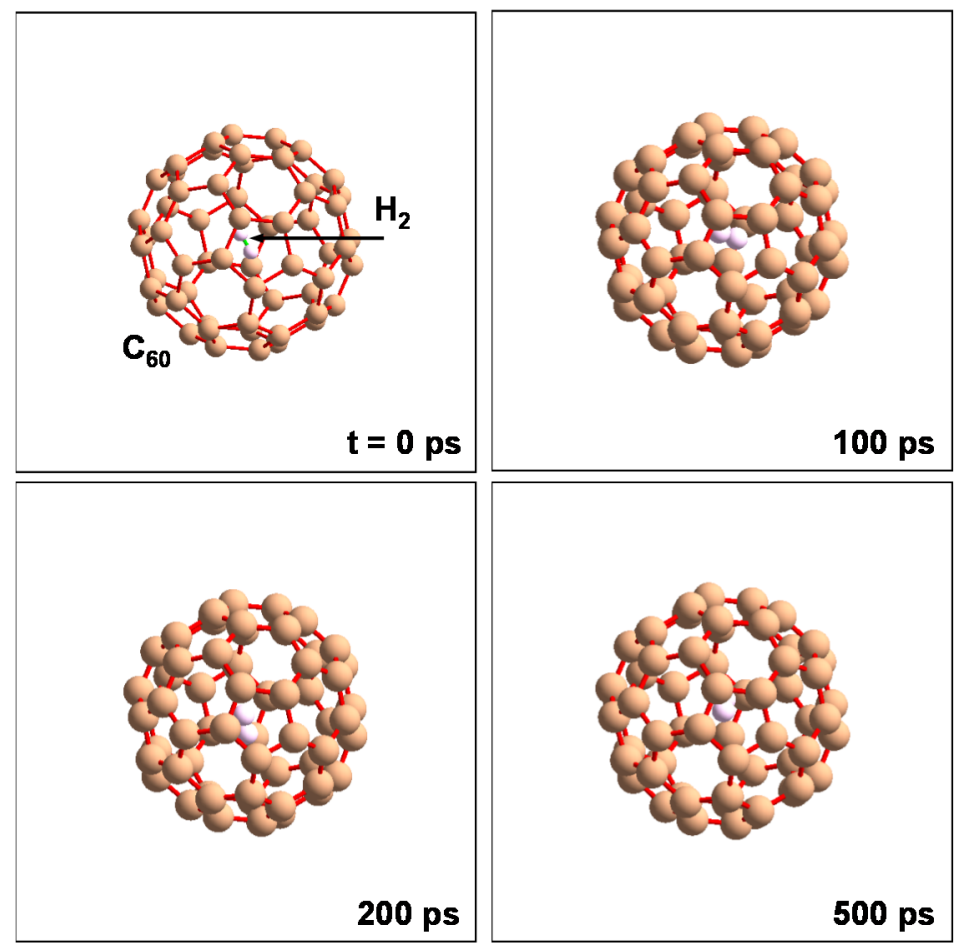

Figure 11. Molecular dynamics calculation to confirm stability of $\mathrm{H}_{2}$ molecule into $\mathrm{C}_{60}$ at $298 \mathrm{~K}$ and $105 \mathrm{~Pa}$. NTP ensembles and organic potential were used in the calculation.
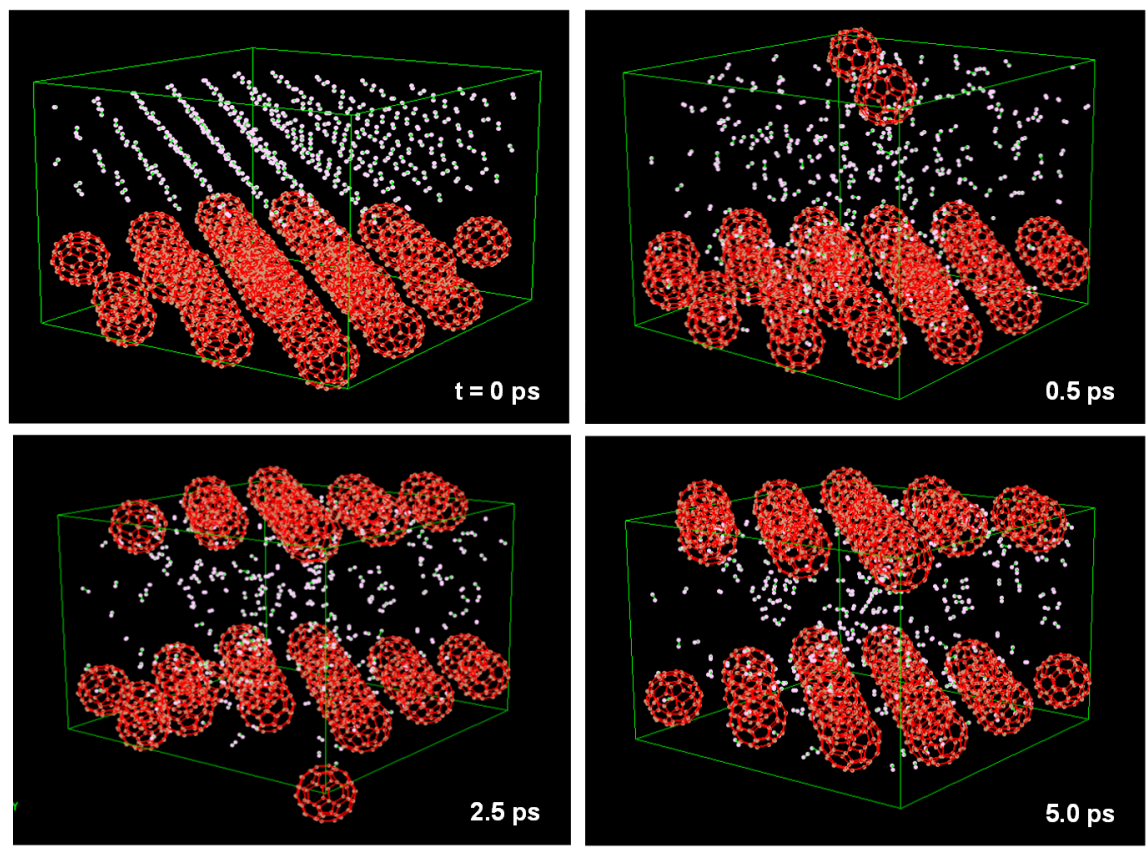

Figure 12. Molecular dynamics calculation to find condition of $\mathrm{H}_{2}$ gas storage. Unit cell is composed from $32 \mathrm{C}_{60}(f c c)$ with $288 \mathrm{H}_{2}$ molecules $(f c c)$. NPH ensembles and organic potential were used in the calculation.

After introducing $\mathrm{H}_{2}$ molecules into the $\mathrm{C}_{60}$ cage at $2.5 \mathrm{ps}$, they are stored and stable in $\mathrm{C}_{60}$. Figure 13 shows a schematic model of a single $\mathrm{H}_{2}$ molecule stored in a hexagonal ring of $\mathrm{C}_{60}$. These results indicate that fullerene-like materials can store $\mathrm{H}_{2}$ gas in cage at $T=298 \mathrm{~K}$ and $P=0.1 \mathrm{MPa}$, and some $\mathrm{H}_{2}$ molecules were stored in the $\mathrm{C}_{60}$ cage when the pressure was greater than $5 \mathrm{MPa}$. It is known that 
$\mathrm{H}_{2}$ molecules are adsorbed on the walls of single-walled carbon nanotubes over $7 \mathrm{MPa}$ as an experimental result [26]. Since a $\mathrm{C}_{60}$ cluster has a large curvature and $\mathrm{H}_{2}$ molecules are very small compared to $\mathrm{C}_{60}$, it is considered that adsorption and storage of $\mathrm{H}_{2}$ gas occur at the same time. Detailed theoretical calculation on hydrogen storage in BN nanomaterials has also been performed [27-31].
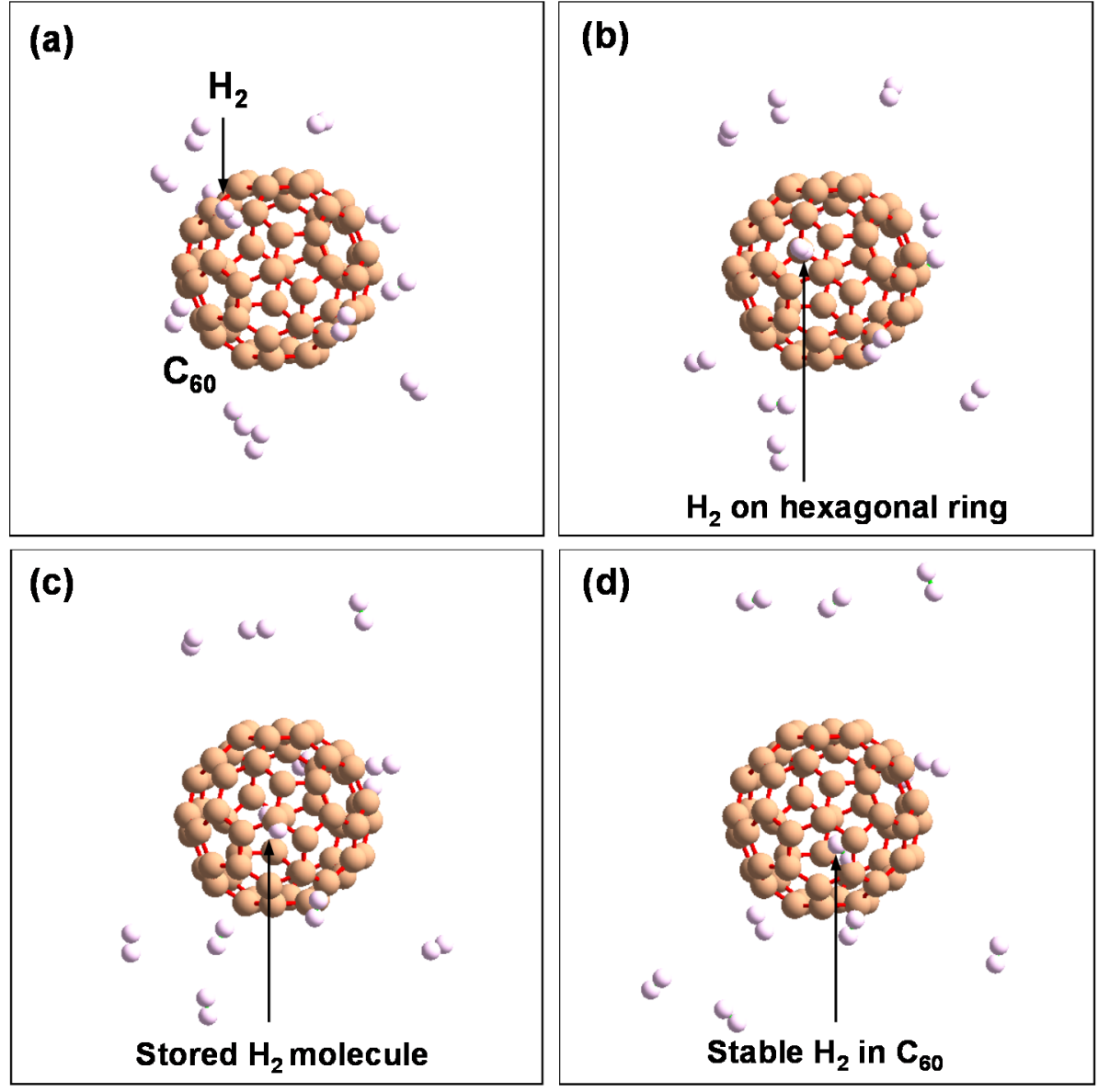

Figure 13. Schematic model of $\mathrm{H}_{2}$ molecule stored in hexagonal ring in the order of $(\mathbf{a}-\mathbf{d})$.

\section{Conclusions}

HREM observation showed the formation of BN nanotubes, nanocapsules and nanocages, which were synthesized from mixtures of $\mathrm{LaB}_{6}, \mathrm{Pd}$, and boron powder by using an arc melting method. Although samples produced with Pd include only BN nanocapsule structures, samples produced with $\mathrm{LaB}_{6}$ present $\mathrm{BN}$ nanocapsule, nanotube and nanocage structures. After separation of $\mathrm{BN}$ nanomaterials using ethanol, hydrogen storage was measured by TG/DTA, and the BN nanomaterials produced from $\mathrm{LaB}_{6}$ and $\mathrm{Pd} /$ boron powder showed possibility of hydrogen storage of $\sim 3 \mathrm{wt} \%$. Energies for $\mathrm{BN}$ and $\mathrm{C}$ clusters with hydrogen were investigated by molecular orbital calculations. Stabilities of these clusters were estimated from the energies, and possibility of $\mathrm{H}_{2}$ storage ability was predicted by these results. $\mathrm{B}_{24} \mathrm{~N}_{24}, \mathrm{~B}_{36} \mathrm{~N}_{36}, \mathrm{~B}_{60} \mathrm{~N}_{60}$ and $\mathrm{C}_{60}$ clusters were selected as the tip structure of the nanotubes. Chemisorption calculation of hydrogen for BN clusters showed that hydrogen bonding with nitrogen atoms was more stable than that with boron atoms, and that hydrogen bonding with tetragonal ring is more stable than that with hexagonal ring. Energy increase by hydrogen addition to $\mathrm{C}_{60}$ is higher compared to $\mathrm{BN}$ clusters because of $\mathrm{C}-\mathrm{H}$ interaction, which indicates that the $\mathrm{BN}$ clusters 
have higher stability with hydrogen atoms. $\mathrm{BN}$ cluster and $\mathrm{C}$ cluster showed possibility of $\mathrm{H}_{2}$ storage of $\sim 4.9 \mathrm{wt} \%$ and $\sim 6.5 \mathrm{wt} \%$, respectively. $\mathrm{H}_{2}$ storage of $\mathrm{C}$ cluster is better than those of BN clusters. However, stability of $\mathrm{H}_{2}$ molecules in $\mathrm{BN}$ clusters might be higher than that of $\mathrm{C}$ clusters. Energies of hydrogenation for $\mathrm{B}_{24} \mathrm{~N}_{24}$ were also investigated by molecular orbital calculations. Chemisorption calculation of hydrogen in the $\mathrm{B}_{24} \mathrm{~N}_{24}$ clusters showed that hydrogen bonding with nitrogen atoms was more stable than that with boron atoms. Chemisorption calculations also indicate that endohedral elements decreased energies of hydrogenation and $\mathrm{Li}$ atom is suitable element for hydrogen chemisorption. Molecular dynamics calculations showed that a single $\mathrm{H}_{2}$ molecule remains in a stable state in a $\mathrm{C}_{60}$ cage at $T=298 \mathrm{~K}$ and $P=0.1 \mathrm{MPa}$. It is confirmed that pressure of over $5 \mathrm{MPa}$ is required to store $\mathrm{H}_{2}$ molecules in a $\mathrm{C}_{60}$ cage. As a result of SPE calculations, $\mathrm{H}_{2}$ molecules enter from hexagonal rings of fullerene-like materials. The energy required of $\mathrm{H}_{2}$ discharge from fullerene-like materials is similar to that of $\mathrm{H}_{2}$ storage. The present study indicates that $\mathrm{BN}$ fullerene materials could be a one of the possible candidates as hydrogen gas storage materials.

\section{Acknowledgments}

The author would like to acknowledge Naruhiro Koi, Masaki Kuno, Ichihito Narita, Masahiro Inoue and Katsuaki Suganuma for excellent collaborative works and useful discussion.

\section{Conflicts of Interest}

The author declares no conflict of interest.

\section{References}

1. Schlapbach, L.; Züttel, A. Hydrogen-storage materials for mobile applications. Nature 2001, 414, 353-358.

2. Dillon, A.C.; Jones, K.M.; Bekkedahl, T.A.; Kiang, H.; Bethune, D.S.; Heben, M.J. Storage of hydrogen in single-walled carbon nanotubes. Nature 1997, 386, 377-379.

3. Chen, P.; Wu, X.; Lin, J.; Tan, K.L. High $\mathrm{H}_{2}$ uptake by alkali-doped carbon nanotubes under ambient pressure and moderate temperatures. Science 1999, 285, 91-93.

4. Dujardin, E.; Ebbesen, T.W.; Hiura, H.; Tanigaki, K. Capillarity and wetting of carbon nanotubes. Science 1994, 265, 1850-1852.

5. Liu, C.; Fan, Y.Y.; Liu, M.; Cong, H.T.; Cheng, H.M.; Dresselhaus, M.S. Hydrogen storage in single-walled carbon nanotubes at room temperature. Science 1999, 286, 1127-1129.

6. Nützenadel, C.; Züttel, A.; Chartouni, D.; Schlapbach, L. Electrochemical storage of hydrogen in nanotube materials. Electrochem. Solid-State Lett. 1999, 2, 30-32.

7. Wu, X.B.; Chen, P.; Lin, J.; Tan, K.L. Hydrogen uptake by carbon nanotubes. Int. J. Hydrog. Energy 2000, 25, 261-265.

8. Oku, T.; Narita, I.; Koi, N.; Nishiwaki, A.; Suganuma, K.; Inoue, M.; Hiraga, K.; Matsuda, T.; Hirabayashi, M.; Tokoro, H.; et al. Boron Nitride Nanocage Clusters, Nanotubes, Nanohorns, Nanoparticles, and Nanocapsules. In B-C-N Nanotubes and Related Nanostructures; Yap, Y.K., Ed.; Springer: Berlin, Germany, 2009; pp. 149-194. 
9. Moussa, G.; Demirci, U.B.; Malo, S.; Bernard, S.; Mielea, P. Hollow core@mesoporous shell boron nitride nanopolyhedron-confined ammonia borane: A pure B-N-H composite for chemical hydrogen storage. J. Mater. Chem. A 2014, 2, 7717-7722.

10. Weng, Q.; Wang, X.; Bando, Y.; Golberg, D. One-step template-free synthesis of highly porous boron nitride microsponges for hydrogen storage. Adv. Energy Mater. 2014, 4, doi:10.1002/aenm.201301525.

11. Moussa, G.; Salameh, C.; Bruma, A.; Malo, S.; Demirci, U.B.; Bernard, S.; Miele, P. Nanostructured boron nitride: From molecular design to hydrogen storage application. Inorganics 2014, 2, 396-409.

12. Liu, Y.; Liu, W.; Wang, R.; Hao, L.; Jiao, W. Hydrogen storage using Na-decorated graphyne and its boron nitride analog. Int. J. Hydrog. Energy 2014, 39, 12757-12764.

13. Lei, W.; Zhang, H.; Wu, Y.; Zhang, B.; Liua, D.; Qin, S.; Liu, Z.; Liu, L.; Ma, Y.; Chen, Y.; et al. Oxygen-doped boron nitride nanosheets with excellent performance in hydrogen storage. Nano Energy 2014, 6, 219-224.

14. Ebrahimi-Nejad, S.; Shokuhfar, A. Compressive buckling of open-ended boron nitride nanotubes in hydrogen storage applications. Phys. E 2013, 50, 29-36.

15. Wang, Y.; Wang, F.; Xu, B.; Zhang, J.; Sun, Q.; Jia, Y. Theoretical prediction of hydrogen storage on Li-decorated boron nitride atomic chains. J. Appl. Phys. 2013, 113, 064309:1-064309:6.

16. Lim, S.H.; Luo, J.; Ji, W.; Lin, J. Synthesis of boron nitride nanotubes and its hydrogen uptake. Catal. Today 2007, 120, 346-350.

17. Oku, T. Direct structure analysis of advanced nanomaterials by high-resolution electron microscopy. Nanotechnol. Rev. 2012, 1, 389-425.

18. Oku, T. High-resolution electron microscopy and electron diffraction of perovskite-type superconducting copper oxides. Nanotechnol. Rev. 2014, 3, 413-444.

19. Oku, T.; Nishiwaki, A.; Narita, I.; Gonda, M. Formation and structure of $\mathrm{B}_{24} \mathrm{~N}_{24}$ clusters. Chem. Phys. Lett. 2003, 380, 620-623.

20. Koi, N.; Oku, T.; Narita, I.; Suganuma, K. Synthesis of huge boron nitride cages. Diam. Relat. Mater. 2005, 14, 1190-1192.

21. Oku, T.; Kuno, M.; Narita, I. Hydrogen storage in boron nitride nanomaterials studied by TG/DTA and cluster calculation. J. Phys. Chem. Solids 2004, 65, 549-552.

22. Oku, T.; Narita, I. Calculation of $\mathrm{H}_{2}$ gas storage for boron nitride and carbon nanotubes studied from the cluster calculation. Phys. B 2002, 323, 216-218.

23. Koi, N.; Oku, T. Hydrogen storage in boron nitride and carbon clusters studied by molecular orbital calculations. Solid State Commun. 2004, 131, 121-124.

24. Koi, N.; Oku, T.; Suganuma, K. Effects of endohedral element in $\mathrm{B}_{24} \mathrm{~N}_{24}$ clusters on hydrogenation studied by molecular orbital calculations. Phys. E 2005, 29, 541-545.

25. Oku, T.; Narita, I.; Nishiwaki, A.; Koi, N.; Suganuma, K.; Hatakeyama, R.; Hirata, T.; Tokoro, H.; Fujii, S. Formation, atomic structures and properties of carbon nanocage materials. Top. Appl. Phys. 2006, 100, 187-216.

26. Ye, Y.; Ahn, C.C.; Witham, C.; Fultz, B.; Liu, J.; Rinzler, A.G.; Colbert, D.; Smith, K.A.; Smalley, R.E. Hydrogen adsorption and cohesive energy of single-walled carbon nanotubes. Appl. Phys. Lett. 1999, 74, 2307-2309. 
27. Sun, Q.; Wang, Q.; Jena, P. Storage of molecular hydrogen in B-N cage: Energetics and thermal stability. Nano Lett. 2005, 5, 1273-1277.

28. Zhou, Z.; Zhao, J.; Chen, Z.; Gao, X.; Yan, T.; Wen, B.; Schleyer, P.R. Comparative study of hydrogen adsorption on carbon and BN nanotubes. J. Phys. Chem. B 2006, 110, 13363-13369.

29. Wu, H.; Fan, X.; Kuo, J.L. Metal free hydrogenation reaction on carbon doped boron nitride fullerene: A DFT study on the kinetic issue. Int. J. Hydrog. Energy 2012, 37, 14336-14342.

30. Wen, S.H.; Deng, W.Q.; Han, K.L. Endohedral BN metallofullerene $\mathrm{M} @ \mathrm{~B}_{36} \mathrm{~N}_{36}$ complex as promising hydrogen storage materials. J. Phys. Chem. C 2008, 112, 12195-12200.

31. Venkataramanan, N.S.; Belosludov, R.V.; Note, R.; Sahara, R.; Mizuseki, H.; Kawazoe, Y. Theoretical investigation on the alkali-metal doped $\mathrm{BN}$ fullerene as a material for hydrogen storage. Chem. Phys. 2010, 377, 54-59.

(C) 2014 by the authors; licensee MDPI, Basel, Switzerland. This article is an open access article distributed under the terms and conditions of the Creative Commons Attribution license (http://creativecommons.org/licenses/by/4.0/). 